\title{
Dotykanie minionego.
} Fortepian Jane Campion jako przykład adaptacji

\section{auratycznej}

Marcin Jauksz

ORCID: 0000-0002-8337-3640

O Świcie wzięłam Psa - i poszłam

Zobaczyć się z Oceanem -

Syreny z wodnych Suteren

Wyszły mi na spotkanie -

Fregaty - z Pierwszego Piętra

Wyciągały Konopne Dłonie -

Biorąc mnie za Mysz - wyrzuconą

Na Piach przez Fale słone -

Nie tknął mnie Nikt - dopiero Przypływ

Podpełzł do Czubka Trzewika -

Rąbka Fartucha - Paska -

Płóciennego Stanika -

Groził, że mnie pochłonie całą -

Jak Rosa, co przemoczyła

Rękaw łodyżki Mlecza -

Wtedy - ja też ruszyłam - 


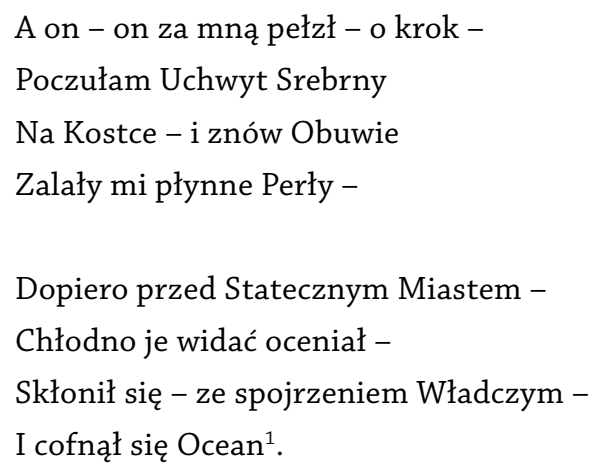

Kobieta na plaży w wierszu Emily Dickinson igra z żywiołem, kusi bóstwa, rozpisuje na rytm kroków emocje drzemiące wobec porannego przypływu. Z codziennej aktywności podejmowanej dla relaksu wyrasta sytuacja specyficznej rozgrywki, którą interpretowano i jako zabawę, która przeradza się w wyścig ze śmiercią ${ }^{2}$ jako ekskursję o konsekwentnie poważnym charakterze, wyprawę, która wyprowadza bohaterkę poza granice cywilizacji, zapraszając ją do wejrzenia w przepaść i zmierzenia się z własnym wnętrzem, „egzorcyzmowania i ćwiczenia świadomości”" ${ }^{3}$ ale też jako metonimię erotycznej gry ${ }^{4}$. Wszystkie te trzy interpretacyjne ścieżki nakładają się równie przekonująco na ślady trzewików bohaterki wiersza, która poruszając się na granicy między tym, co znane („Stateczne Miasto”), a tym, co niepokojące i agresywne (grożący pochłonięciem Ocean), chociaż też kuszące (perły), kroczy ścieżką pozwalającą na wyznaczenie granicy tęsknoty i potrzeb, określenia dynamiki między światem swoim a tym, który leży gdzieś dalej, poza znaną okolicą.

Dickinson w wierszu O świecie wzięłam psa - i poszłam... ustawia swoją bohaterkę między dwoma domami - tym swoim i tym oceanicznym, też po swojemu podzielonym. Piwnica zamieszkana przez Syreny i pierwsze piętro, po którym suną Fregaty, nakładają na mit płynności wyobrażoną strukturę i może także hierarchię swoistej intymności. Piętrom oceanu odpowiadają piętra człowieka, które posuwając się wzwyż i dotykając kolejnych warstw ubrania, odkrywa Przypływ. Erotyzmem tę scenę nasycają rozliczne konotacje mityczne pozwalające rozpoznać gwałt, jaki bohaterce Dickinson ma zadać Ocean. Jednakże - stopy zanurzone w pianie morskiej przywołują scenę narodzin Afrodyty i pozwalają myśleć o słowach wiersza, które samopoznanie łączą z eksploracją własnej wrażliwości erotycznej.

Stopniowo sięgający coraz wyżej dotyk przypływu w cytowanym wierszu spotkać chciałbym z coraz śmielej poczynającymi sobie dłońmi George’a Bainesa, jednego z dwóch mężczyzn, którzy walczą o uczucie Ady, głównej postaci w Fortepianie Jane Campion. To jego determinacja i zdobycie najcenniejszej na całym świecie dla Ady rzeczy - fortepianu - pozwalają mu wykorzystać jej obecność i wywalczyć tę ukazaną w wierszu chwilę, kiedy dotyk oceanu przenika coraz wyżej i wyżej... Rozbieranie Ady przebiega etapami, podczas kolejnych wizyt w domu George'a, za każdą z nich odzyskuje cząstkę instrumentu, na którym bohaterka podczas tych spotkań gra.

${ }^{1}$ Emily Dickinson, Wiersze wybrane, tłum. Stanisław Barańczak (Kraków: Znak, 2000), 135.

2 James Reeves, „Preface”, w Emily Dickinson, Selected Poems, red. James Reeves (London: Heinemann, 1959$), 1$.

${ }^{3}$ Kenneth Stocks, Emily Dickinson and the Modern Consciousness (Houndmills: Macmillan, 1988), 87. Tu i wszędzie dalej, o ile nie podano inaczej, przekład mój- M.J.

${ }^{4}$ Zob. Linda Wagner-Martin, Emily Dickinson. A Literary Life (Palgrave: Macmillan, 2013), 68. 
Moment, w którym mężczyzna dotyka jej po raz pierwszy, może być tu wyróżniony. On kładzie się pod fortepianem, obok jej trzewika duszącego pedał instrumentu, prosząc, domagając się, by Ada coraz to wyżej podniosła suknię, zaczynając, co ważne, od skrawka skóry widocznego dzięki maleńkiej dziurce w pończosze ${ }^{5}$. Zbliżenie na fragment skóry i brudny paznokieć Bainesa buduje szczególne wrażenie na widzu. Rozdarta bielizna i brudny palec tchną realizmem, ale też naruszeniem reguł romansu, epokowego decorum uwodzenia. Naturalistyczne obrazowanie Campion momentami wykorzystuje symbolicznie (nowozelandzkie błoto, w którym co rusz zapada się bohaterka), czasami jednak, wydaje się, w trosce o poczucie realnego naruszania granic, które staje się udziałem jej postaci. W filmie kostiumowym, w którym, jak pisała Stella Bruzzi, „same ubrania stają się znaczącymi elementami kontrapunktowego, zseksualizowanego dyskursu"6, brud i ubóstwo wyczytane z bielizny stają się wyrazem epoki naznaczonej czułością w najmniej oczywistych miejscach. Bo Baines, przy całej swej determinacji, próbuje jednocześnie być delikatny; zdobywa Adę krok po kroku, kawałek po kawałku (ubrania), etapami (skóry odkrywanej). Trochę jak Ocean w wierszu Dickinson, chociaż stateczniej. Nie raz Ada spłoszona ucieka, ale jednak zawsze wraca, nawet wtedy, gdy już odzyska fortepian. Może zresztą - przede wszystkim wtedy. Zmityzowana, poetycka geneza Ady jako branki pozwala wskazać - skandaliczny z perspektywy części przynajmniej feministycznych odczytań ${ }^{7}$ - kontekst kulturoznawczy akcentujący wolę ofiary w porządku mitycznym, w którym kobieta, niby zwierzyna łowna, jak pokazuje Jean-Paul Roux z „uszczęśliwionym spojrzeniem”, zwraca się ku oprawcy, myśliwemu, który jest kojarzony z drapieżnym kotem czy ptakiem.

Dziewica wie, jak uciekać. Kobieta dojrzała chętniej daje się złapać: straciła swą siłę i nie musi już bronić cnoty. Epickie i mitologiczne legendy dużo mówią o porwaniach: przydarzyły się Io. Europie, Medei, Helenie, a Herodot [...] ironizuje: „Porywać niewiasty jest czynem ludzi niesprawiedliwych, ale z powodu porwanych uprawiać dzieło zemsty mogą tylko nierozumni, gdyż gdyby same nie chciały, nie zostałyby uprowadzone”. [...] Wszystkie ludy o tradycyjnej kulturze wiedzą, że dzika zwierzyna nie da się pojmać ani zabić wbrew swej woli, daremne jest wówczas polowanie. Tak jest i z kobietą. Gdy się wzbrania, gdy wygrywa wyścig, nie ma co nalegać. Merlin miłuje Vivianę. Lecz chce, by przyszła do niego dobrowolnie, próbuje ją uwieść. Nieustannie o nią zabiega, a ona coraz bardziej go nie znosi ${ }^{8}$.

George'owi pozornie tylko daleko do potęgi mitycznych porywaczy często wyłaniających się z oceanu oraz cynicznych mieszczan paryskiej czy londyńskiej socjety, którzy dostosowywali

\footnotetext{
${ }^{5}$ Fortepian (1993), reż. Jane Campion, 00:44:40. Dalej odwołania do fragmentów filmu zaznaczane bezpośrednio w tekście, oznaczone skrótem F. i podaniem godziny, minuty i sekundy filmu.

${ }^{6}$ Stella Bruzzi, Undressing Cinema. Clothing and Identity in the Movies (London: Routledge, 1997), 36. Bruzzi zwraca też uwagę na scenę pierwszej pieszczoty: „Ten gest jest, na jednym poziomie, bardzo otwartym wyrażeniem pożądania Ady przez Bainesa, na co Ada reaguje zaskoczeniem, ale nie zniesmaczeniem widocznym na twarzy w kolejnym ujęciu. Jego erotyzm jednak, jako obrazu kinowego bardziej niż idei, jest kreowany przez wielość przeciwstawień koloru i faktury: dwie skóry (jednak męska i śniada, druga kobieca, «biała i gładka jak jajko»), głęboka czerń pończochy i delikatne, choć nieco niedbałe, wykończenie na białej halce Ady”. Bruzzi, xiii.

${ }^{7}$ Według Carolyn Gage Alisdair Stewart jest „brutalnym gwałcicielem”, ale Bainesowi przysługuje u niej przydomek „obleśnego gwałciciela” (ang. Sleazy), sam film zaś, mimo szlachetnych ambicji „zmienia trakt i staje się popierającym gwałt kawałkiem heteronormatywnej i patriarchalnej propagandy". Cyt. za: Harriet Margolis, " "A Strange Heritage»: From Colonization to Transformation?”, w Jane Campion's „The Piano", red. Harriet Margolis (Cambridge: Cambridge University Press, 2000), 28.

8 Jean-Paul Roux, Kobieta w historii i micie, tłum. Barbara Szczepańska (Warszawa: Volumen, 2010), 230.
} 
swe zabiegi o serce kobiety do informacji, które o niej posiadali ${ }^{9}$. Jego przewaga nad Adą, którą pozyskuje nader szybko, prześcigając tu legalnego męża bohaterki o dwie długości, zasadza się na rozpoznaniu znaczenia, jakie ma dla niej fortepian. W odróżnieniu od mitycznych czy salonowych uwodzicieli jednak - George się swej władzy zrzeknie. To, co dostanie, wymuszając zbliżenie, nie jest tym, czego w istocie chce. W opowieści Campion ofiara nie jest szczęśliwa tak długo, jak do przychodzenia jest zmuszona, przyciągana przez fortepian. Baines też tego nie chce i być może dlatego, ostatecznie, jego mądrość, przy całym jego nieokrzesaniu, większa jest niż legendarnego Merlina, o którym wspomina Roux. George jest sprytny i pod wieloma względami równie wyrachowany jak Heathcliff z Wichrowych Wzgórz Emily Brontë, ale jego łagodność każe mu raczej pogodzić się z utratą ukochanej, gdy traci wiarę w to, że będzie w stanie ją odzyskać.

Ważniejszy jednak wydaje się, gdy czyta się wypowiedzi samej reżyserki, charakter tła, na którym odbywa się miłosny dramat Ady i George'a. Choć nowozelandzki busz zastępuje tu angielskie wrzosowiska, obie przestrzenie można uznać za równie atrakcyjne dla rozegrania tej opowieści o miłości podszytej przemocą i tęsknotą. W rozmowie z Campion Miro Bilbough pytał ją, w kontekście faktu, że powieść Brontë powstawała w tym samym czasie, w którym dzieje się akcja filmu, o „epokowy strumień świadomości”, jakby okalający glob cały. Autorka Fortepianu zgadza się z sugestią:

Czułam ekscytację wobec pasji i romantycznej wrażliwości opisywanej przez pisarzy i pisarki takich jak Emily [Brontë]. Wydawało mi się, że można bez problemu przeszczepić to do sytuacji, w której toczy się moja opowieść, Nowej Zelandii lat pięćdziesiątych XIX wieku.

Czuję, że mam wielki dług u ducha Emily Brontë. I być może nie tylko u niej, ale i u Emily Dickinson, z innych powodów. [...] Tak jak Emily Dickinson żyła w ukryciu, podobnie jest z moją bohaterką, Adą. Jest zamknięta nie dlatego, że ukryła się w pokoju, ale ponieważ nie mówi ${ }^{10}$.

Samotność bohaterów, ich oderwanie od świata Solidnego Miasta czyni ich pokrewnymi duszami. Oboje są wyrzutkami. Gdy przybywa na wyspę, Ada zostaje, niby fortepian, który jest dla niej tak drogi, zniesiona na plażę przez załogę statku, którym przypływa, jak przedmiot. Zostawiona na plaży przez nieokrzesanych marynarzy jedynie w towarzystwie swej córeczki Flory spędza tam noc, czekając na nieznanego jej męża i dopełnienie się jej losu, którego przewrotności (rozdzielenie $\mathrm{z}$ fortepianem) nie jest jeszcze w stanie przewidzieć. Podobnie jak przypływu, który zaskakuje i ją, i Florę. Z mężem i Maorysami zatrudnionymi w roli tragarzy przybędzie jednak też George i to dla niego, niby bohaterka Dickinson, narodzi się z morskiej piany. Gdy mężczyzna zgodzi się jakiś czas później zabrać ją na plażę jako przewodnik i zobaczy ją grającą na tle żywiołu, zrodzi się uczucie i zacznie rozgrywka, którą Campion wypełni cały film.

\footnotetext{
${ }^{9}$ Zob. Jean Claude Bologne, Historia uwodzenia. Od Antyku do dziś, tłum. Katarzyna Marczewska (Warszawa: Oficyna Naukowa, 2012) 257, 263.

${ }^{10}$ Miro Bilbrough, Jane Campion, „The Piano”, w Jane Campion Interviews, red. Virginia Wright Wexman (Jackson: University Press of Missisipi, 1999), 115. To, że odcięcie się od świata, którego znaczenie podkreśla tu Campion, jest ważkim wspólnym mianownikiem obu autorek, współcześni badacze i badaczki podkreślają z przekonaniem. Margaret Homans pisała: „Żadna z kobiet-poetek w tej epoce nie prowadziła życia, które ktokolwiek nazwałby zwyczajnym. Emily Brontë i Emily Dickinson przyjęły ograniczenia, jakie nakładały na nie okoliczności; Brontë, opierając się każdej wyprawie poza dom jej ojca, i Dickinson, kultywująca nawet głębsze jeszcze odosobnienie". Margaret Homans, Women Writers and Poetic Identity. Dorothy Wordsworth, Emily Brontë and Emily Dickinson (New Jersey: Princeton University Press, 1980), 16.
} 
Fortepian na przestrzeni ostatnich trzydziestu niemalże lat obrósł w sporą bibliografię i interpretacje tego niezwykłego filmu pozwalają na w miarę komfortowe pomijanie oczywistości w uważnej lekturze ${ }^{11}$. Na pewno jednak trudno jest wyczerpująco omówić dzieło, które po swojemu stawia sobie za zadanie wymknąć się widzowi i uniknąć przyszpilenia ważkich kwestii. „Zatrzaskują mnie w prozie - / Tak jak - gdy byłam mała - / Zamykali w Komórce - / Abym „cicho siedziała” - mówi w jednym z wierszy Dickinson, chwytając problem filozoficzny związany z ujmowaniem podmiotu, wobec którego również można czytać historię Ady. Proza w ujęciu Dickinson przeciwstawiona jest językowi jej oszczędnej, intensywnej poezji. Proza nie równa się tu, rzecz jasna narracji jako takiej, ale pojawić się może pytanie o powieść jako punkt odniesienia tak wyraziście zmieniającą charakter literackiej i artystycznej komunikacji, której losy w swych pismach śledził Walter Benjamin, a którego wnioski stanowić mają fundament przewartościowania, zauważalnego między innymi dzięki Fortepianowi w sztukach wizualnych tego ostatniego przełomu wieku. Jak pisze Ryszard Różanowski:

Pojawienie się powieści w epoce nowożytnej jest dla Benjamina jedną z pierwszych oznak upadku sztuki opowiadania jako przekazu doświadczeń. [...] Słowo mówione przestaje być uprzywilejowanym medium, opowiadanie nie wymaga uprzywilejowanej obecności opowiadającego, czytelnik zaś jest równie samotny jak autor. Powieści się nie opowiada ${ }^{12}$.

Dla filozofa, dla którego elementem kluczowym było doświadczanie sztuki in statu nascendi rozwój druku i prywatyzacja poznawania opowieści oznaczała początek przekształceń kulturowych, których odpowiednikiem w obrębie sztuk wizualnych będzie wynalezienie fotografii, a następnie ożywienie jej w medium filmowym. Utrata kontaktu z materialnym dziełem lub obecnością artysty związana z reprodukowalnością techniczną dzieła sztuki określać będzie przemianę, którą Benjamin określił jako zanik aury u progu XX wieku. W swoim słynnym eseju, do dziś uznawanym za ważny punkt odniesienia dla kulturoznawców i filmoznawców, pisał:

Technika reprodukcji, można to ująć ogólnie, wyrywa reprodukowane z dziedziny tradycji. Ponieważ zostaje ono powielone w reprodukcji i na miejscu jego wyjątkowego występowania pojawia się w formie masowej. Pozwalając zaś reprodukcji wychodzić naprzeciw widzowi w jego aktualnej sytuacji, aktualizuje reprodukowanie. Oba te procesy prowadzą do potężnego wstrząśnięcia tym, co przekazywane - do wstrząśnięcia tradycją, które jest odwrotną stroną współczesnego kryzysu i odnowienia ludzkości. Są one jak najściślej związane z ruchami masowymi naszych dni. Ich najpotężniejszym agentem jest film. Jego znaczenie społeczne, nawet w swej najbardziej pozytywnej formie i właśnie w niej, jest nie do pomyślenia bez jego aspektu destrukcyjnego katartycznego: likwidacji wartości tradycji w dziedzictwie kulturowym ${ }^{13}$.

Myśl o kinie, które mimo ambicji adaptowania przyczynia się do procesu gubienia wagi kapitału kulturowego, to punkt odniesienia, ale nie punkt zobowiązujący. Jak pisała Laura U. Marks

\footnotetext{
${ }^{11}$ Zob. m.in. cytowany wyżej tom zbiorowy Jane Campion's „The Piano”. W Polsce jedną z pierwszych akademickich interpretacji autorstwa Elżbiety Ostrowskiej znaleźć można w tomie Sztuka interpretacji klasycznych i współczesnych dzieł filmowych (Łódź: Centralny Gabinet Edukacji Filmowej Dzieci i Młodzieży, 1995).

${ }^{12}$ Ryszard Różanowski, Pasaże Waltera Benjamina. Studium myśli (Wrocław: Wydawnictwo Uniwersytetu Wrocławskiego, 1997), 199-200.

${ }^{13}$ Walter Benjamin, „Dzieło sztuki w okresie jego reprodukowalności technicznej”, w Walter Benjamin, Twórca jako wytwórca. Eseje i rozprawy, tłum. Robert Reszke (Warszawa: Wydawnictwo KR, 2011), 27-28.
} 
film lub video można uznać za posiadające aurę, gdyż jest to materialny artefakt obiektu, któremu daje świadectwo. Dlatego można powiedzieć, że kino działa jak fetysz w antropologicznym sensie opisanym przez Williama Pietza: przedmiot, którego moc do reprezentowania czegoś pochodzi z przywileju wcześniejszego kontaktu z tym czymś $^{14}$.

Fortepian, w którym tytułowy instrument nosi wszelkie znamiona fetyszu, fikcyjność przedstawionej historii zasadniczo mogłaby osłabiać jego aurę - Marks w swych badaniach kina odczuwalnego również dotykiem skupia się wszak przede wszystkim na dokumentach lub produkcjach z pogranicza fikcji i dokumentalnej rejestracji. Tu jednak pojawia się kwestia intertekstualnej sieci, w którą autorka wplata swą opowieść.

Podziwiam wrażliwość Dickinson i Brontë, którą wnoszą w swe dzieła i którą dają światu. Obie były samotnicami i trzymały się tej wrażliwości, płacąc za to każda swoją cenę. W pewien sposób czuję się jak szarlatan, bo mogę żyć wesołe życie, jako że jestem dość towarzyska. Wykorzystuję i wkładam ich ciężką pracę w bardziej popularną i akceptowalną formę; i czasem czuję się winna, myśląc, że to wykorzystanie jakoś kazi ich czystą mądrośćc ${ }^{15}$.

Trop deprecjacji współczesności względem „złotego wieku XIX” z jednej strony zachęcałby do przywołania Georga Steinera i jego kulturowych diagnoz dotyczących współczesności. Jednak fakt, że „wina”, którą odczuwa autorka jest jedynie chwilowa, pozwala myśleć inaczej o tym adaptowaniu myśli ważnych dla siebie pisarek. W kontekście wyrażonego pokrewieństwa i jednoczesnej niepewności autorskiej Campion można raz jeszcze postawić pytanie o możliwości rezurekcji auratyczności jako podskórnej ambicji wszystkich tych, którzy historie swe osadzają w kontekście przeszłej kultury i tworzenia opowieści usiłujących wyrazić „realną obecność" minionego; nawet jeśli narzędziem tegoż jest interpretacyjna spekulacja nad echami doświadczeń zapisanymi w literaturze - intertekstualna gra. Gdy motywem artystycznego przedsięwzięcia staje się skupiony namysł nad przeszłością, którą dzięki pamiątkom i zapisanym wspomnieniom można sobie wyobrazić, to, co pozornie utracone bezpowrotnie, może stać się przedmiotem estetycznej negocjacji.

Adaptowanie czasu bezpowrotnie straconego, dostrajanie jego wizji do możliwości poznawczych współczesnego odbiorcy, skonfrontowanie tegoż z porządkiem odległym w czasie, to punkt wyjścia do aranżowania materialnych znaków przeszłości w celu lepszego pojęcia wspólnoty horyzontów, jaka połączyć może współczesnych z minionymi. Ambicja uchwycenia aury czasów działa pod prąd przemian, które do utraty aury przez dzieła sztuki, w ujęciu Benjamina, prowadzą. Duch czasów również post-auratycznych łączy się nierozerwalnie z nadzieją ewokacji obecności. Paradoksalnie zatem - reprodukowalność dzieła i brak kontroli nad ostatecznym jego wykonaniem wymuszają o wiele bardziej skupioną reżyserię, pozwalającą stworzyć coś, co pulą swych znaczeń dorówna sile artefaktu, który „naprawdę” zrodziłaby przeszłość. Fakt, że tym, co adaptowane, nie jest konkretny tekst, a raczej synergia szeregu lekturowych doświadczeń, które ubrane zostają w fabułę pokrewną tym, generowanym przez

\footnotetext{
${ }^{14}$ Laura U. Marks, The Skin of the Film. Intercultural Cinema, Embodiment, and the Senses (Durham: Duke University Press, 2000), 20-21.

${ }^{15}$ Jane Campion Interviews, 116.
} 
epokę, ale jednak odrębną, nakładać się tu może zwłaszcza na efektywność kolektywnych działań artystycznych (filmu, komiksu, teatru...), gdzie wypadkowa wielu energii twórczych prowadzi do powstania jednego (mniej lub bardziej spójnego) utworu.

Fortepian zaczyna się, przypomnieć warto, od dysonansu percepcyjnego. Widzowi zająć może chwilę, by zorientować się, że pierwsze spojrzenie, jakie rzuca na świat przedstawiony to spojrzenie przez palce. Patrzy bohaterka i patrzy widz... razem z nią, dzięki niej. W jakimś więc sensie także z niepokojem i obawą (zasłanianie twarzy, niepatrzenie jako wyraz lęku), w jakimś z intencją zaproszenia do zabawy (w chowanego). „Głos, który słyszycie - mówi zza kadru dziecko - nie jest głosem, którym mówię. To mój głos wewnętrzny” [F. 00:01:15]. Ta wypowiedź to też siedlisko paradoksów. Postać, która odcina się od świata na tyle sposobów, jednocześnie chce o sobie opowiedzieć. Pozycja wyjściowa Ady - niby dziecka skulonego pod drzewem - niesie w sobie równie wiele symbolicznych treści, co jej przybycie na plażę i oczekiwanie na los, który został napisany przez kogoś innego. Jednocześnie już na plaży właśnie, we wspólnym czuwaniu kobiety i jej córki, ujęta zostaje estetyczna nadzieja, ukazana w zjawiskowej plamce światła, jaką tworzy prowizoryczny namiot-lampion odcinający się na tle zmierzchu. On skupia uwagę i pozostaje w pamięci, wyróżnia się niby fortepian wyniesiony z morza i pozostawiony na pustej plaży.

Campion zmusza widza, by w tych pierwszych scenach doświadczył całego spektrum emocji: wraz z Adą ciekawsko patrzy przez palce na córkę uczącą się jazdy na kucyku, obok niej kuli się pod surowym spojrzeniem gospodyni w domu jej ojca, które ucina grę na pianinie, obok niej i jej córki może wzdrygnąć się, gdy obserwuje z jednej strony wymiotujące dziecko, z drugiej, jak marynarze wspólnie oddają mocz na plaży... Kinowy obraz i dźwięk współdziałają w spektaklu, zmierzającym do fizycznego wymiaru obu doświadczeń, zarysowania horyzontu również rzeczy wstrętnych, które są ważnymi etapami na trasie tej wyprawy. Tak jak pisała Carol Jacobs w jednej z pierwszych akademickich reakcji na nagrodzoną produkcję: „to jest film, który nalega na nas, byśmy zobaczyli. Jak pies znęcony spod werandy podczas ciężkiej burzy, nie możemy się nie zamoczyć” ${ }^{16}$. Z jednej strony haptyczność sugerowanego tu doświadczenia estetycznego można strywializować, z drugiej jednak polityczność filmu Campion pozwala na specyficzne metafory sugerujące zaangażowanie po stronie widza. Na zmysł dotyku Campion oddziałuje od pierwszego ujęcia, pokazując świat, który w synergii z dotykiem pozwala się opowiedzieć, a może i - odtworzyć - z ducha realistycznej mimesis i romantycznej ewokacji.

Za konsekwencję gry palców przesłaniających światło w pierwszych ujęciach filmu można uznać chwile, gdy dotykają klawiszy fortepianu, przestrzeni dawnych (z ojcem Flory) i bieżących (z George'em) zbliżeń. Zmysłowe interakcje poczynają się u Campion w detalu, zbliżeniu; te spełnione, ale też te, które nacechowane są rozczarowaniem. Przykładem może być choćby znakomita scena, w której Stewart dzieli się przy herbacie z ciotką Morag wątpliwościami co do stanu psychicznego swej żony po tym, jak przyłapał ją na „grze” na blacie kuchennym. Dys-

${ }^{16}$ Carol Jacobs, „Playing Jane Campion's Piano: Politically”, MLN vol. 109, nr 5 (1994): 759. 
kretna rozmowa prowadzona przy innych (w tym przy Bainsie, który przysłuchuje się znad swojej filiżanki) łączy się z jednej strony z delikatną grą przedmiotów, które łagodzą niepokój (wachlarz, herbata), z drugiej są elementami maskowania obawy przed szaleństwem. Dwa ważkie ujęcia blisko finału tej sceny to zbliżenie na pokazywaną przez pryzmat nerwowego drgającego wachlarza dłoń Morag przyłożoną do jej serca i filiżankę Alisdaire’a, pokazaną z góry (z jego pochylonej perspektywy). Gdy miesza mleko, mówi: „Można przecież uznać i ciszę za coś dobrego", wyrażając za chwile nadzieję, że z czasem jego żona okaże mu więcej czułości [F. 00:28:15]. Obawa Stewarta przed szaleństwem jest po części lękiem Lintona o Katarzynę, której nic nie jest w stanie powstrzymać przed wychylaniem się w noc ku Wichrowym Wzgórzom i Heathcliffowi. Jest też odegraniem kulturowej przemocy, o której w jednym z wyróżnionych przez Campion wierszy mówiła:

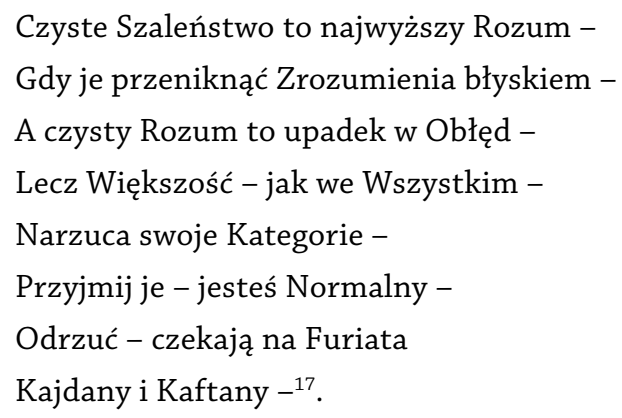

„Zrozumienia błysk” w przekładzie Stanisława Barańczaka zastępuje „a dicerning Eye” - bystre oko; fakt, na który warto zwrócić uwagę w kontekście myślenia o kinie jako wcieleniu duchowych diagnoz poetki wschodzącej nowoczesności. Uważność spojrzenia to klucz do odnalezienia się w świecie bohaterów Fortepianu, w świecie urządzanym przez Campion. „Salonowa narada" określa kategorie, które przyjąć lub odrzucić musi Ada, ale oczywiste jest od samego początku, że nie jest ona z tego świata, że kategorie jej męża, zostawiającego fortepian na plaży, nie są tymi jej. Podejrzenie „upośledzenia umysłowego” w obliczu sygnalizowanej potrzeby instrumentu jest naturalną diagnozą w przestrzeni kolonialnego domostwa. Fakt, że muzyka to język, w którym Ada komunikuje swoje nastroje, objawi się rozmówczyni Stewarta, starej Morag, do pewnego stopnia nieco później, gdy wyrazi przed Nessie swoje odczucia związane z „wnikającą w człowieka” muzyką. I to jednak będzie miało charakter wykroczenia w świecie, w którym sztuka jest i ma pozostać jedynie dystrakcją i rozrywką.

W scenie narady nad stanem psychicznym Ady, w której wyrażone erotyczne nadzieje Alisdaire'a pozwalają Bainsowi na ukucie jego planu o przejęciu fortepianu i zaskarbieniu tym samym atencji niezwykłej kobiety, Campion zapowiada wiele romantycznych (szalonych) przewartościowań. Przedmioty wszak w takim ujęciu komunikują emocje, lęki i nadzieje bohaterów - drżą wraz z nimi, odzwierciedlając niepewność, która ich toczy ${ }^{18}$. Gdy po cięciu

\footnotetext{
${ }^{17}$ Dickinson, Selected Poems, 111.

${ }^{18} \mathrm{Jest}$ to ciekawy szereg, gdyż kolonialna przestrzeń tego silącego się na elegancję „salonu” wyraża się poprzez tradycyjnie salonowe przedmioty - wachlarz, serwis do herbaty, meble... To, o czym rozmawiają bohaterowie, domniemane zaburzenie Ady, łączy się jednak też z przedmiotem „salonowym”, fortepianem. Instrument ten jednak przez fakt swej nieporęczności ma pozostać w dziczy. Dyskwalifikacja Ady dokonuje się pomimo jej potencjalnego powinowactwa $\mathrm{z}$ tym, do czego koloniści chcieliby aspirować.
} 
montażowym u kresu sceny spadnie siekiera, rozpoczynając swoją drogę od zwykłego przedmiotu codziennego użytku, przez symbol kary za ciekawość i wiarołomstwo w inscenizacji baśni o Sinobrodym aż po realne narzędzie kary wymierzonej Adzie za jej przewiny, Campion rozstawione będzie miała wszystkie elementy na szachownicy swojego dramatu, w którym ludzie i przedmioty odgrywają momentami równorzędną rolę. Fortepian to jeden z tych filmów, w których, jak pisała Marks, „haptyczne obrazy zachęcają do bardziej ucieleśnionego i multisensorycznego związku z obrazem”, gdyż „połączenie widzialnego z dźwiękiem, ruchami kamery i montażem wywołuje zmysłowe efekty"19.

Tu wrócić warto do Benjamina, którego przemianowanie teorii dokonane przez Marks pozwala na inne spojrzenie na przedmioty zreprodukowane przez kino. Choć oderwane od swojego czasu, ich kulturowa autentyczność i zdolność oznaczania przeszłości (zwłaszcza wspólnotowej) nie musi być zażegnana. Wspólną przestrzenią w obrębie każdej epoki może być codzienność i zwyczajność, którą podszyta bywa i najbardziej spektakularna epika. Różanowski zauważał:

Benjamin lubił tajemnicę, ale fascynowały go jednocześnie najbardziej niepozorne detale, zwyczajne przedmioty należące do codziennego świata. Był to nie tyle przejaw osobistej skłonności, ile metody, z pomocą której miał nadzieję z jednej strony przedstawić nagłą przemianę wnętrza przestrzeni w jego stronę zewnętrzną, $\mathrm{z}$ drugiej zaś przedstawić to, co wydaje się znane, pospolite i swojskie, jako faktycznie nierozpoznane albo rozpoznane w sposób fałszywy ${ }^{20}$.

Co ważne - nowozelandzka przygoda Ady jest drogą od wnętrza (głosu utajonego, zapośredniczonego) ku temu, co na zewnątrz; z głębi „duszy”, czymkolwiek by ona była, utaknej z symbolicznych obrazów początku widz zmierza ku zmysłowemu przeżywaniu rzeczywistości, od błota, w którym trudno się nie zapaść, po ekstazę miłosną i nagie ciało drugiego człowieka. Miłość, którą sprowokuje (to lepsze słowo niż „obudzi”) w niej Baines, wyrasta z tego, co zmysłowe właśnie; droga do tajemnicy Ady - być może ustala to bohater już podczas wspólnej z Adą i Florą wyprawy na plażę - wiedzie przez jej skórę, dotknięcie, które odczuwalne jest na najmniejszym już jej skrawku, odsłoniętym przez bezwstydną pończochę. Romantyczne tropy miłości zostają tu skomplikowane przez odkrywane w wieku XIX biologiczne wymiary przeżywania świata przez człowieka. I choć „antymieszczańskość”, „dzikość” pogardzanego za swe bratanie się z Maorysami Bainesa jako kochanka jest tu elementem konwencjonalnym ówczesnych romansów - trop wykorzystany też przez Emily Brontë w niezmiennie ważnych Wichrowych Wzgórzach ${ }^{21}$ - to jednak jego sposób na zbudowanie kanału porozumienia z kobietą, którą chce zdobyć, poświadcza wrażliwość i szczególne powinowactwo „myśliwego” z „ofiarą". Przemieszczająca się między dwoma domami bohaterka, niby w powieści Brontë, musi ostatecznie odkryć siebie. W narcystycznej scenie zatopienia się we własne oblicze w lustrze, które całuje, dopełnia przebudzenia i jednocześnie rozpoznaje siebie. Tak jak wcześniej zrobił to jej kochanek.

\footnotetext{
${ }^{19}$ Marks, The Skin of the Film. Intercultural Cinema, Embodiment, and the Senses, 172.

${ }^{20}$ Różanowski, Pasaże Waltera Benjamina. Studium myśli, 216-217.

${ }^{21}$ Zob. Carmen Pérez Riu, „Two Gothic Feminist Texts: Emily Brontë’s Wuthering Heights and the film, The Piano, by Jane Campion", Atlantis vol. XXII, nr 1 (2000): 163-173.
} 
Czyniąc tę historię o miłosnym podboju z jednej strony przedsięwzięciem, które jak w powieści Brontë pozostaje w silnym związku z ekonomicznymi realiami wspólnoty, w której się rozgrywa, z drugiej zaś relacją, gdzie zrozumienie dla nośników uczuć i wartości ma ogromne znaczenie, Campion pozwala przełożyć swoją adaptację ducha połowy XIX wieku również na poziom namysłu nad regułami opowiadania. Uwagi Niklasa Luhmana o kodowaniu miłości przełożyć się mogą na zrozumienie, jak wykorzystanie powieściowych i poetyckich kodów wrażliwości dziewiętnastowiecznej pozwala stworzyć auraptację - opowieść z dawnych czasów, której wtedy nie było:

Funkcją miłości jako medium komunikacji jest umożliwienie tego, co skądinąd nieprawdopodobne. W języku potocznym funkcja ta zostaje zaszyfrowana jako „rozumienie”, daje o sobie znać tam, gdzie mowa o pragnieniu zrozumienia i gdzie skarga na brak zrozumienia każe wykroczyć poza granice tego, co bezpośrednio możliwe. Skoro zaś podejmowane są próby takiego wykraczania poza elementy prostej obserwacji, to zrozumiałe staje się, dlaczego ostatecznie odrzucone zostają wszystkie obiektywne, uogólnione wyznaczniki miłości, jak zasługa, uroda, cnota, a zasada umożliwiająca to, co mało prawdopodobne, jest coraz bardziej personalizowana. Medium posługuje się osobą. Trzeba ją znać tak dobrze, jak to tylko możliwe, aby uchwycić lub chociażby przypuścić, co stanowi jej świat własny i co funkcjonuje jako schemat porównawczy 22 .

Luhmann zaznacza jednocześnie, że desubstancjalizacja podmiotu w wieku XVIII sprawia, że „Innego trzeba ujmować w doniesieniu do funkcjonującego dlań otoczenia i dla siebie samego”23. Ta zmiana, którą w kostiumie romansu opowiada także Fortepian, przekłada się na definiowanie porozumienia estetycznego, jakie proponuje Campion w swoim filmie. Jeśli zagadnienie medialności ujmowane w filmie przez pryzmat sfetyszyzowanego instrumentu nałożyć na Benjaminowską obawę o depersonalizację relacji ze sztuką u progu XX wieku, można zasugerować, że opowieść o Adzie, tematyzując między innymi problem komunikacji, daje szansę na skrystalizowanie przypadku nowego typu doświadczenia estetycznego zasadzającego swą rację na podjętej próbie odtworzeniu więzi z (wydawałoby się) utraconymi formułami wrażliwości.

Rozwinięciem tego są wymieniane przez bohaterów i z samymi sobą (w lustrze) spojrzenia bohaterek i bohaterów. Wykorzystany przez Campion motyw ślubnej fotografii i towarzyszące mu przymiarki sukni wskazuje na dziewiętnastowieczną kulturę spektaklu; patrzenie na siebie bohaterów ujmuje ich doświadczenia w ramy nowych sposobów postrzegania człowieka rodzących się w XIX wieku. Brak ceremonii, jak sugeruje jedna z postaci, można sobie zrekompensować, choćby po części wspólną fotografią. Kontrapunktem dla tego stwierdzenia jest jednak smutek spojrzenia widzącej swe odbicie w lustrze ubranej w białą suknię Ady i jednocześnie drugie spojrzenie, które biegnie od strony lustra: małej Flory, naburmuszonej, złej, pełnej wyrzutów... [F. 00:16:15]. Dziewczynka ma wiele powodów do złości, jednak to na ten ostatecznie wyrażony można zwrócić uwagę - jej niespełnione pragnienie, by być na fotografii, łączy się z potrzebą atencji, uwagi skupionej na niej właśnie (z tego niezadowolenia wyrośnie też ostatecznie jej bunt przeciw matce i zdrada, której się dopuści). Fotografia, która ma potwierdzić los Ady, cenzuruje obecność dziecka i manipuluje historią, zastępując realne

\footnotetext{
${ }^{22}$ Niklas Luhmann, Semantyka miłości, tłum. Jerzy Łoziński, w Antropologia ciała. Wybór tekstów, red. Małgorzata Szpakowska (Warszawa: Wydawnictwa Uniwersytetu Warszawskiego, 2008), 244.

${ }^{23}$ Luhmann, Semantyka miłości.
} 
doświadczenie ślubnej ceremonii artefaktem. Jednocześnie jest jednak próbą przypomnienia tych pierwszych portretów, które dla samego Benjamina były jeszcze nosicielami aury mimo dehumanizującego oka obiektywu. Campion pokazuje nam jednak oko, które patrzy przez obiektyw, tworząc sytuację, która rozwinięta pozwala zupełnie myśleć o zapośredniczonym doświadczeniu ujętym przez reprodukowalne dzieło sztuki. U jego źródeł leży możliwość rozpoznania, poczucie sytuacji, która udzielona zostaje patrzącemu (w miejsce fotografa) widzowi, nagle obecnemu tuż obok, na granicy montażowego przejścia. Tu też, jak ów pies z metafory recepcji ukutej przez Jacobs, widz ma odczuć dyskomfort bycia wystawionym na deszcz łączący się z niechęcią Ady, by być tam w ogóle: w Nowej Zelandii, przed domem Stewarta, w błocie, w ulewie, przed obiektywem...

Druga połowa XIX wieku to początek przemian w myśleniu o obiektywizmie doświadczenia wzrokowego ${ }^{24}$. Kontekst dla przywoływanej perspektywy Benjamina budują odkrycia na gruncie psychologii widzenia rozwijane w ostatnich dekadach długiego stulecia. Wyczerpanie się dotychczasowych modeli epistemologicznych przełoży się na filozoficzne koncepcje podmiotu oraz mającej ambicje odzwierciedlenia jego doświadczeń sztuki. Jak pisała Dorota Łuczak:

załamanie się gwarancji apriorycznej jedności poznawczej świata wiąże się z pojawieniem przygodnej i psychologicznej zdolności syntezy i kojarzenia. Oznacza to, że apodyktyczne postrzeganie całości świata zastępują zmienne stosunki sił wymykających się kontroli podmiotu ${ }^{25}$.

Tego rodzaju rozbudzone żywioły Campion pokazuje dyskretnie. Scena, w której Ada wychodzi z domu, po tym jak Alisdaire prosi o zagranie „jakiejś piosenki” albo „gigi”, kamera pokazuje ją przez okno, snującą się po błotnym podwórku. Następne ujęcie to najazd na plecy bohaterki i jej złożone z tyłu ręce oraz, ostatecznie, tył głowy, przez który widz jakoby przenika do obrazu cichego, szumiącego lekko pod naporem wiatru lasu [F. 01:07:37]. Alisdaire nie rozumie kobiety, która odmawia traktowania fortepianu jako narzędzia jego rozrywki; to, czym instrument się stał w minionych tygodniach, to, jakie znaczenia niósł dla niej wcześniej, sprawia, że prośba męża jest swoistą profanacją... Ona wymyka się roli, którą chce się jej przypisać, ucieka na granicę buszu, tu być może, jeśli poszukać interpretacyjnie wsparcia w poezji Dickinson, odnajduje więź z inaczej nieobecnym w Fortepianie Absolutem. Postawa muzycznej maestrii, nałożona na protetyczny dla Ady charakter fortepianu, pozwala się być może odkryć dzięki ostatniemu dwuwersowi wiersza On gmera w twojej Duszy:

On gmera w twojej Duszy

Jak Muzyk - co trąca dla próby

\footnotetext{
${ }^{24}$ „Jesteśmy dzisiaj w pełni świadomi, że fotografia nie jest neutralną rejestracją widzialnego, ale wytworem urządzenia wymyślonego specjalnie do wizualnego utrwalania i porządkowania pewnych aspektów - i tylko pewnych aspektów - świata zewnętrznego. Ponadto operator dokonuje wyborów i podejmuje wiele decyzji (dotyczących motywu, kadrowania, optyki, emulsji fotograficznej, czasu pozowania, nie wspominając o tym wszystkim, co dotyczy odbitek), od których zależy obraz fotograficzny. W momencie pojawienia się fotografii widziano w niej niekwestionowane ukazanie tego, co jest, pozytywnej prawdy. Fotografia i jej szczególny sposób przedstawiania cieszyły się bezwarunkowym zaufaniem”. Henri Zerner, „Spojrzenie artystów”, w Historia ciała. T. 2. Od rewolucji do I wojny światowej, red. Alain Corbin, tłum. Krystyna Belaid i Tomasz Stróżyński (Gdańsk: słowo/obraz terytoria, 2013), 99.

${ }^{25}$ Dorota Łuczak, Foto-oko. Wizja fotograficzna wokół okulocentryzmu w sztuce I połowy XX wieku (Kraków: Universitas, 2018), 136-137.
} 


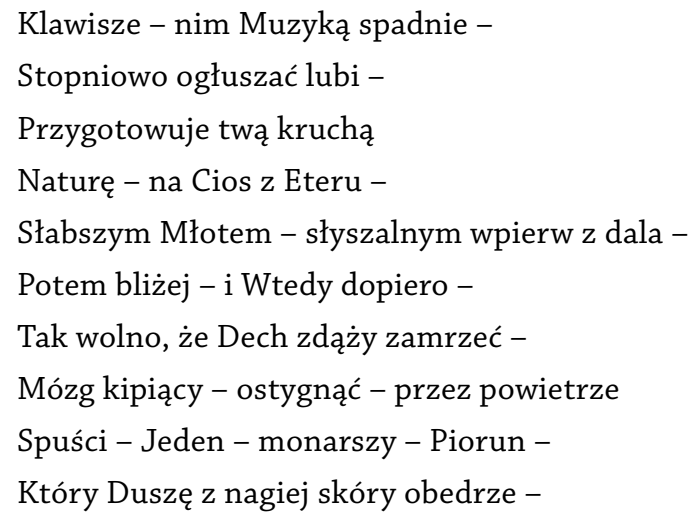

Gdy Wiatr bierze Las w swoje Łapy -

Wszechświat trwa nieruchomo - bezwietrznie $-{ }^{26}$.

Naturalistyczne, zmysłowe żywioły, które biorą Adę w posiadanie, łączą się tu z harmonijnym zawieszeniem - ekstazy? orgazmu? Nagość ciała w filmie Campion, nagość pozyskiwana, nagość strzeżona i oddawana nie temu, któremu jest należna, przywołuje kluczowe mity miłosne zachodniej tradycji, jednocześnie zdradzając wyrachowanie twórców, pozwalających im uwieść przede wszystkim widza. Protetyczny charakter fortepianu jako głosu u źródeł opowieści i faktyczna proteza, w którą Baines w jej życiu „pośmiertnym” zaopatrza Adę, dopełniają listę tematycznych fascynacji dziewiętnastowiecznych fikcji o nadawaniu zmysłowej formy ulotnym marzeniom. Jak pisał Antoine de Becque:

właściwością kina jest nagrywanie ciał i opowiadanie za ich pomocą historii, co oznacza czynienie ich chorymi, monstrualnymi oraz - niekiedy równocześnie - niezwykle przyjemnymi i pociągającymi. Surowy zapis, podobnie jak umieszczenie w fikcji, polega na tej chorobie i jej urodzie, które przyjmują postać przerażającego oszpecenia lub idealnego przeobrażenia. Frankenstein w pewnym sensie ma się do fikcji filmowej, jak Oblany ogrodnik do migawek z życia braci Lumière: przygoda cielesna, która budzi historię. Twórcy kina jarmarcznego pojęli to bardzo wcześnie, jeszcze przed wielkimi producentami kina niemego: gapie przychodzą oglądać ciało na ekranie, toteż jeżeli to możliwe, powinno ono być dziwne, przerażające, imponujące, wspaniałe, perwersyjne, rozkoszne. To relacja bezpośrednia i zarazem obowiązkowa: ciało eksponowane w kinie jest pierwszym śladem wiary w spektakl, a zarazem miejscem, w którym spektakularność ujawnia się przede wszystkim²7.

To, że z dzisiejszej perspektywy chce się polemizować z oderwaniem od romantycznych źródeł obecności, jakie, w myśl diagnozy Benjamina, oznaczało to dla sztuki, wyrasta z doświadczenia kina o ileż bardziej zmysłowego i dotykalnego. Proces adaptowania właściwy ponowoczesnej kulturze łączy się z chęcią przewartościowania i tych fetyszystycznych poczuć autora Pasaży. Wyrasta też z ducha tego ostatniego fin-de-siècle’u i momentu, w którym proces przerabiania i adaptowania zyskuje, jak pokazywała między innymi Julie Sanders, „specyficzny rytm i znaczenie”. Stało się to „w następstwie postmodernistycznej teorii późnego wieku dwudziestego,

\footnotetext{
${ }^{26}$ Dickinson, Selected Poems, 73.

${ }^{27}$ Antoine de Baecque, „Ekrany. Ciało w kinie”, w Historia ciała. Tom 3. Różne spojrzenia. Wiek XX, red. JeanJacques Courtine, tłum. Krystyna Belaid i Tomasz Stróżyński (Gdańsk: słowo/obraz terytoria, 2014), 349-350.
} 
która uczyniła nas stale świadomymi procesu interwencji i interpretacji związanego z każdą relacją lub uwikłaniem się w istniejący wcześniej tekst" ${ }^{28}$. Jednocześnie jednak pogodziło z renegocjacją dotyczącą potrzeby podmiotowości w dziele sztuki, ludzkiego pierwiastka, namacalności... Te dwie tendencje finału wieku XX dla „nowych Wiktorian” Fortepian spełnił doskonale:

Począwszy od tytułu po sfetyszyzowany przedmiot z tytułu, od niedającej spokoju, momentami przytłaczającej ścieżki dźwiękowej do wskazania na stłumioną mowę, dźwięk i jego brak nasycają Fortepian surrealną aurą emocjonalnej intensywności. Solowe wykonania utworów na pianinie przez Holly Hunter uderzają z równą mocą co jej zdolność do przekazania tak szerokiego spektrum emocji w całkowitej ciszy. Tak jak jej postaci, Ady, [...] niemota, obecność ewokacyjnych „naturalnych" dźwięków funkcjonuje niemalże jako osoba - fale oceanu uderzające o nagie wybrzeże, nieprzerwany deszcz uderzający w dachy, egzotyczne ptaki nawołujące przez gęsty las niby kontrapunkt dla braku ludzkiej konwersacji. Podobnie poleganie Campion na akcie patrzenia jako zabiegu kinematograficznym oznacza zarówno świadomość czegoś, jak i odmowę poznawania, to, co może być zobaczone, i to, czego zobaczyć nie wolno. Percepcja zatem zdaje się funkcjonować jako wizualna ontologia filmu, paralelnie do jego nieustępliwie emocjonującej ścieżki dźwiękowej².

Słowo „aura” użyte przez badaczkę nie konotuje tu znaczenia Benjaminowskiego. Ale dzięki teoretycznemu przewartościowaniu dokonanemu przez Marks można przyłożyć do feerii znaczeń opisanych powyżej myśl o odkrywaniu doświadczeń w fabule nasyconej symbolicznymi artefaktami rozpiętymi na tkance intertekstów z minionych form kultury. „Auratyczny charakter rzeczy - pisze Marks - to ich zdolność nie tyle do wskrzeszania wspomnień jednostki, ale zawarcia w sobie historii społeczeństwa we fragmentarycznej formie"30.

Wskazana zależność między obrazem i dźwiękiem jako sferami percepcji budującymi wrażenie w filmie Campion na zasadzie przedefiniowania sposobów, w jaki splatają się te wymiary w życiu, pozwala szukać w takich interpretowanych założeniach doświadczenia estetyczno-filmowego fundamentu przywołania anachronicznych z perspektywy autora Dzieła sztuki w dobie jego reprodukowalności technicznej sposobów przeżywania utworów artystycznych. Spojrzenie widza $\mathrm{w}$ interakcji z postaciami i przestrzeniami auraptacji $\mathrm{w}$ idealnym scenariuszu reaktywuje za pomocą medium, które wyjściowo miało przynieść ze sobą zanik aury, elementy doświadczenia estetycznego wyczytane z epoki przejściowej, jaką był XIX wiek. Samoświadomość epoki pozwala twórcom symbolicznie rekonstruować, grając tematami w obrębie technicznych możliwości nowych mediów, intensywne wrażenie obecności. Zbliżenia na detale w filmie Campion obok świadomego wykorzystania elementów ówczesnej kultury, na które uwrażliwiają ją dzieła autorek takich jak Dickinson czy Brontë, dodatkowo w połączeniu z historią bohaterki, wkraczającej (na wszystkich płaszczyznach) w nowy, egzotyczny dla niej świat, budują strukturę napięć właściwą odkrywaniu tego, co długo pozostawało utajone, a po przeszło stu latach przez (re)konstrukcje fabuł nieziszczonych ma szansę otworzyć wrota do XIX stulecia.

\footnotetext{
${ }^{28} \mathrm{Julie}$ Sanders, Adaptation and appropriation (Abington-New York: Routledge, 2006), 148.

${ }^{29}$ Reshela du Puis, „Romanticizing Colonialism. Power and Pleasure in Jane Campion's The Piano”, The Contemporary Pacific vol. 8, nr 1 (1996): 57.

${ }^{30}$ Marks, The Skin of the Film. Intercultural Cinema, Embodiment, and the Senses, 120.
} 


\section{Bibliografia}

Baecque, Antoine de. „Ekrany. Ciało w kinie”. W Historia ciała. Tom 3. Różne spojrzenia. Wiek XX. Zredagowane przez Jean-Jacques Courtine. Przetłumaczone przez Krystyna Belaid i Tomasz Stróżyński, 347-367. Gdańsk: słowo/obraz terytoria, 2014.

Benjamin, Walter. Twórca jako wytwórca. Eseje i rozprawy. Przetłumaczone przez Robert Reszke. Warszawa: KR, 2011.

Bologne, Jean Claude. Historia uwodzenia. Od Antyku do dziś. Przetłumaczone przez. Katarzyna Marczewska. Warszawa: Oficyna Naukowa, 2012.

Bruzzi, Stella. Undressing Cinema. Clothing and Identity in the Movies. London: Routledge, 1997

Dickinson, Emily. Wiersze wybrane.

Przetłumaczone przez Stanisław Barańczak. Kraków: Znak, 2000.

Homans, Margaret. Women Writers and Poetic Identity. Dorothy Wordsworth, Emily Brontë and Emily Dickinson. New Jersey: Princeton University Press, 1980.

Jacobs, Carol. „Playing Jane Campion's Piano: Politically”. MLN vol. 109, nr 5 (1994): 757785.

Jane Campion Interviews. Zredagowane przez Virginia Wright Wexman, Jackson: University Press of Missisipi, 1999.

Luhmann, Niklas. „Semantyka miłości”. Przetłumaczone przez Jerzy Łoziński. W Amtropologia ciała. Wybór tekstów. Zredagowane przez Małgorzata Szpakowska, 242-247. Warszawa: Wydawnictwa Uniwersytetu Warszawskiego, 2008.

Łuczak, Dorota. Foto-oko. Wizja fotograficzna wokół okulocentryzmu w sztuce I połowy XX wieku. Kraków: Universitas, 2018.

Margolis, Harriet. „ «A Strange Heritage»: From Colonization to Transformation?". W Jane Campion's „The Piano”. Zredagowane przez Harriet Margolis, 1-41. Cambridge: Cambridge University Press, 2000.

Marks, Laura U. The Skin of the Film. Intercultural Cinema, Embodiment, and the Senses, Durham: Duke University Press, 2000.

Puis, Reshela du. „Romanticizing Colonialism. Power and Pleasure in Jane Campion's The Piano", The Contemporary Pacific vol. 8, nr 1 (1996): 51-79.

Reeves, James. „Preface”. W Emily Dickinson. Selected Poems. Zredagowane przez James Reeves, vii-lii. London: Heinemann, 1959.

Riu, Carmen Pérez. „Two Gothic Feminist Texts: Emily Brontë's Wuthering Heights and the film, The Piano, by Jane Campion". Atlantis vol. XXII, nr 1 (2000): 163-173.

Roux, Jean-Paul. Kobieta $w$ historii i micie. Przetłumaczone przez Barbara Szczepańska, Warszawa: Volumen, 2010.

Różanowski, Ryszard. Pasaże Waltera Benjamina. Studium myśli. Wrocław: Wydawnictwo Uniwersytetu Wrocławskiego, 1997.

Sanders, Julie. Adaptation and appropriation. Abington-New York: Routledge, 2006.

Stocks, Kenneth. Emily Dickinson and the Modern Consciousness. Houndmills: Macmillan, 1988.

Wagner-Martin, Linda. Emily Dickinson. A Literary Life. London: Palgrave Macmillan, 2013.

Zerner, Henri. „Spojrzenie artystów”. W Historia ciała. T. 2. Od rewolucji do I wojny światowej. Zredagowane przez Alain Corbin. Przetłumaczone przez Krystyna Belaid i Tomasz Stróżyński, 79-108. Gdańsk: słowo/ obraz terytoria, 2013. 


\title{
SEOWA KLUCZOWE:
}

\author{
A D A P T A C J A \\ wiek XIX \\ materialność \\ intertekstualność
}

\begin{abstract}
Abstrakt:
Artykuł jest próbą zdefiniowania zjawiska w światowym kinie współczesnym, które wykorzystując nowe sposoby komunikacji w obrębie sztuk wizualnych i ich haptyczności, stara się rekreować nastroje i wrażliwości konotowane z kulturą minionych czasów. Fortepian Jane Campion, jako świadectwo zaangażowanej lektury przede wszystkim poezji Emily Dickinson, ale też Wichrowych Wzgórz Emily Brontë, staje się tu przykładem fabuły z jednej strony nasyconej perspektywami, motywami i sytuacjami zaczerpniętymi z tych utworów, z drugiej wykorzystuje stylistyczną multisensoryczność kina, by w przedstawionych bohaterach i przedmiotach ich otaczających odtwarzać dynamikę relacji i nastroje znane z przekazów o kulturze połowy XIX wieku. Dzięki temu staje się auraptacją (adaptacją auratyczną; ang. auraptation - auratic adaptation), adaptacją aury wyczytanej spomiędzy literackich świadectw epoki, przeniesieniem w dzisiejsze czasy i właściwe im media niepowstałej w wieku XIX opowieści.
\end{abstract}




\section{F E T Y S Z \\ film i pisarstwo kobiece}

\section{NOTA O AUTORZE:}

Marcin Jauksz - literaturoznawca i filmoznawca, adiunkt w Zakładzie Literatury Pozytywizmu i Młodej Polski Uniwersytetu im. Adama Mickiewicza w Poznaniu. W 2010 r. obronił rozprawę doktorską Krytyka dziewiętnastowiecznego rozumu. Źródła i konteksty „Pałuby” Karola Irzykowskiego, nagrodzoną w Konkursie im. Konrada i Marty Górskich w 2011 r. i opublikowaną cztery lata później przez wydawnictwo Universitas. Interesuje się psychologizmem w prozie późnego wieku XIX i kształtującymi się wówczas zasadami kompozycji dzieła literackiego oraz filmowymi fabułami o dojrzewaniu na progu XXI stulecia. Stypendysta rządu francuskiego w latach 2008-2009 oraz programu Fulbright w latach 2018-2019. Publikował między innymi w „Wieku XIX”, „Porównaniach”, „Lampie” i „Polonistyce”. 